\title{
NATUREZA DO CONHECIMENTO E CURRÍCULO PODEROSO NO ENSINO TÉCNICO-PROFISSIONAL: UMA ANÁLISE SOCIOLÓGICA A PARTIR DO CASO DE MOÇAMBIQUE*
}

\author{
Nelson Casimiro Zavale ${ }^{1}$
}

\begin{abstract}
RESUMO: O presente artigo examina a natureza do conhecimento poderoso e os processos epistémicos e sociais subjacentes ao currículo do ensino técnico-profissional (ETP). Teoricamente, o artigo revisita criticamente o conceito de conhecimento poderoso enraizado no realismo social, e baseia-se na teoria de diferenciação curricular de Shay. Empiricamente, o artigo baseia-se na reforma do ETP em Moçambique e procede à reinterpretação das anteriores análises sociológicas da reforma. $\mathrm{O}$ artigo conclui que, no ETP, o currículo poderoso pode resultar da combinação de várias formas de conhecimento, nomeadamente teórico, prático, profissional e genérico; o currículo do ETP resulta da recontextualizaçáo dessas formas de conhecimento, por meio de processos de regulação social.
\end{abstract}

Palavras-chave: Ensino técnico-profissional. Realismo social. Conhecimento poderoso. Teoria de diferenciação curricular. Processos epistémicos e sociais.

\section{NATURE OF POWERFUL KNOWLEDGE AND CURRICULUM IN TECHNICAL, PROFESSIONAL AND VOCATIONAL TRAINING: A SOCIOLOGICAL ANALYSIS BASED ON THE MOZAMBICAN CASE}

ABSTRACT: This paper examines the nature of powerful knowledge and the epistemic and social processes underlying the curriculum of technical and vocational education and training (TVET). Theoretically, the paper revisits critically the concept of powerful knowledge, rooted in social realism, and makes use of Shay's theory of curriculum differentiation. Empirically, the paper re-examines earlier sociological analysis made to

\footnotetext{
*O artigo baseia-se no estudo feito no âmbito do projecto de pesquisa intitulado "Inovaçôes académicas e pedagógicas na formação de professores da educação agrária em Moçambique”, financiado pelo Fundo de Desenvolvimento Institucional do Ministério da Educação de Moçambique à Faculdade de Agronomia e Engenharia Florestal da Universidade Eduardo Mondlane. O artigo foi redigido na Suíça, no âmbito de uma bolsa pós-doutoral denominada "Swiss Government Excellence Scholarship for Foreign Students", financiada ao autor pelo Governo da Confederaçáo Suíça.

${ }^{1}$ Universidade Eduardo Mondlane, Faculdade de Educaçáo - Maputo, Moçambique.

E-mails: nelson.casimiro.zavale@gmail.com; nezava@yahoo.com.br

DOI: 10.1590/ES0101-73302017152968
} 
TVET reform in Mozambique. The paper argues that, in TVET, the powerful curriculum may result from a combination of different forms of knowledge, namely theoretical, practical, professional and generic; the curriculum of TVET results from the recontextualisation of these forms of knowledge, through processes of social regulation.

Keywords: Technical and vocational education and training. Socialrealism. Powerful knowledge. Theory of curriculum differentiation. Epistemic and social processes.

\section{LA NATURE DE LA CONNAISSANCE ET LE CURRICULUM PUISSANT DANS L'ENSEIGNEMENT TECHNIQUE ET PROFESSIONNEL : UNE ANALYSE SOCIOLOGIQUE À PARTIR DU CAS DU MOZAMBIQUE}

RESUMÉ: Cet article analyse la nature de la connaissance puissante et les processus épistémiques et sociaux sous-jacents au curriculum de l'enseignement technique et professionnel (ETP). Théoriquement, l'article revisite de façon critique le concept de connaissance puissante, enraciné dans le réalisme social, et il se sert de la théorie de différentiation curriculaire de Shay. Empiriquement, l'article réexamine les analyses sociologiques antérieures faites à l'égard de la réforme de l'ETP au Mozambique. L'article conclut que, pour l'ETP, le curriculum puissant peut dériver de la combinaison de différentes formes de connaissances, notamment celles qui sont théoriques, pratiques, professionnelles et génériques ; le curriculum de l'ETP dérive de la recontextualisation de ces formes de connaissances, à travers les processus de régulation sociale.

Mots-clés: Enseignement technique et professionnel. Réalisme social. Connaissance puissante. Théorie de différentiation curriculaire. Processus épistémiques et sociaux.

\section{Introdução}

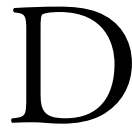

esde o final da década 1990, defensores do realismo social — adiante designados por social-realistas — na sociologia da educação (SED) e do conhecimento têm criticado a tendência de negligenciar o conhecimento teórico nos currículos escolares (YOUNG, 2008; MATON, 2013; MOO$\mathrm{RE}, 2013)$. Os social-realistas defendem que as formas de conhecimento têm valor epistemológico diferente. Diferenciam, por exemplo, o conhecimento teórico do conhecimento quotidiano. O primeiro é concebido como sendo um conjunto de conceitos abstractos, capazes de ordenar factos; o segundo, pelo contrário, é considerado contextual, imediato e assistemático. Devido a tais diferenças, os 
social-realistas defendem que nem todas as formas de conhecimento deviam ser integradas nos currículos. Existem formas de conhecimento cujas propriedades as tornam mais poderosas.

No ensino técnico-profissional (ETP), as teses social-realistas resultaram em críticas contra reformas curriculares inspiradas pela globalização neoliberal, particularmente em países como a Inglaterra, África do Sul e Austrália (YOUNG, 2008; WHEELAHAN, 2009; 2010), incluindo Moçambique (ZAVALE, 2013b). $\mathrm{O}$ argumento comum dessas críticas é o de que as reformas curriculares neoliberais conduzem a uma noção mais instrumentalista e pragmática do conhecimento, que resulta na tendência de negligenciar o conhecimento teórico. As críticas social-realistas ajudaram a reconsiderar o papel do conhecimento teórico no currículo, incluindo no ETP.

Contudo, para o debate curricular, o realismo social deixou algumas questóes não resolvidas. Conforme refere Shay (2012, p. 4-5), a teoria social-realista de diferenciação de conhecimento não se traduziu numa teoria de diferenciação curricular: o realismo social não explicita os princípios que orientam a selecção das diferentes formas de conhecimento integradas nos diferentes tipos de currículos (ex. currículo disciplinar, profissional e genérico). No ETP, o realismo social não responde particularmente às seguintes questōes: Que formas de conhecimento devem ser integradas no currículo do ETP? O que significa "conhecimento poderoso" no ETP? Que processos epistémicos e sociais condicionam o currículo do ETP? O presente artigo procura abordar essas questóes, descrevendo a natureza do "conhecimento poderoso" do ETP, assim como os processos epistémicos e sociais que lhe são subjacentes. Conceptualmente, o artigo baseia-se no modelo de diferenciação curricular de Shay (2012). Empiricamente, o artigo faz o reexame das anteriores análises sociológicas do novo currículo de ETP, introduzido em 2006 em Moçambique (ZAVALE, 2013b).

\section{Contexto da introdução e características do novo currículo de ensino técnico-profissional em Moçambique}

A análise dos processos epistémicos e sociais condicionantes do novo currículo do ETP em Moçambique e a descrição da natureza do "conhecimento poderoso" no ETP requerem uma descrição preliminar do contexto que levou à introdução, em 2006, do novo currículo de ETP. Dois factores justificaram a sua introdução. O primeiro foi a mudança de paradigma socioeconómico. Em meados da década de 1980 — após vigência, desde a independência em 1975, de um Estado socialista monopartidário -, Moçambique adoptou políticas neoliberais e o multipartidarismo. $\mathrm{O}$ fraco desempenho económico, a mudança na liderança governamental e o fim da Guerra Fria e da guerra civil perfilam entre os acontecimentos que fundamentaram a mudança (ABRAHAMSON; NILSON, 1995). 
Uma descrição exaustiva da emergência do neoliberalismo em Moçambique está para além dos objectivos deste artigo (para uma descrição detalhada, ver ZAVALE, 2013a). Importa referir que o neoliberalismo em Moçambique foi introduzido no contexto dos programas de reajustamento estrutural (PREs), introduzidos na África nas décadas de 1980 e 1990, sob os auspícios do Banco Mundial e do Fundo Monetário Internacional (FMI). Os PREs visavam a superar a estagnação económica, a corrigir o intervencionismo estatal e a liberalizar as economias africanas (BOND, 2005). A institucionalização do neoliberalismo trouxe reformas na gestão e nos conteúdos da educação, traduzidas na privatização, comercialização e flexibilização da oferta da educação (LANGA; ZAVALE, 2015; ZAVALE, no prelo; LANGA, 2012). O novo currículo do ETP foi introduzido para ajustar o ETP ao novo contexto sociopolítico e económico. O segundo factor que levou à introdução do novo currículo são as características do ETP antes da reforma. O governo Moçambicano acusa o antigo currículo do ETP de ser incapaz de satisfazer as demandas de uma economia de mercado e informal e da agenda da luta contra a pobreza (REPÚBLICA DE MOÇAMBIQUE, 2001). Tal acusação não é exclusiva de Moçambique. Um pouco por toda a África, agências internacionais e governos aperceberam-se da marginalização do ETP (e do ensino superior), sobretudo nos anos 1980 e 1990, em razáo da política de priorização do ensino primário e de programas de educaçáo para todos. A partir do final da década de 1990, com a intensificação da globalização, advento da sociedade de conhecimento e programa de alívio à pobreza, essa visão mudou, levando a reformas no ETP, no sentido de torná-lo mais flexível e capaz de responder às necessidades do mercado (ATCHOARENA; DELLUC, 2002).

Assim, em Moçambique, a reforma curricular, denominada Programa Integrado da Reforma do Ensino Técnico-Profissional (PIREP), foi introduzida visando a "facilitar a transição do actual sistema de ETP, baseado na oferta, para um sistema baseado na procura" (ZAVALE, 2013b, p. 629). Isso significa que as instituiçóes do ETP seriam menos autónomas quanto ao tipo de programas a oferecer, e passariam a oferecer programas procurados pelo mercado de trabalho. Nesse sentido, o desenho do currículo implicaria a análise do mercado do trabalho para identificar as necessidades em termos de conhecimentos/competências, a descrição de tarefas e actividades desempenhadas por cada profissão, a inventariação de referenciais profissionais e a elaboração dos currículos. Zavale (2013b, p. 629) refere que os novos currículos, apesar do seu tamanho (podem ter até 250 páginas), foram construídos considerando quatro aspectos:

- A organização de conhecimentos em competências genéricas e específicas;

- A expressão, sob forma de verbos (ex. demonstrar, realizar etc.), dos resultados de aprendizagem;

- A clarificação dos contextos de aplicação dos resultados de aprendizagem;

- A referência a evidências empíricas para a avaliação do grau da aquisição das competências. 
Para ilustrar essas características, Zavale (2013a, p. 630) compara o antigo com o novo currículo, o que lhe permite constatar as seguintes diferenças:

- O antigo currículo é mais disciplinar (por ex., "Lingua Inglesa”), enquanto no novo o conhecimento toma a forma de verbos activos (por ex., "usar inglês para situaçôes pessoais, profissionais e sociais"). No novo currículo, o conhecimento disciplinar encontra-se presente, mas numa lógica interdisciplinar. São as competências a desenvolver que demandam conhecimento disciplinar; dado que as competências requeridas dificilmente se encontram numa única disciplina, justapóe-se conhecimento oriundo de diferentes disciplinas;

- O novo currículo é mais flexível. No antigo currículo, a incorporação de inovaçóes era lenta; no novo, sempre que uma pesquisa de mercado identificar novas necessidades de formaçáo, novos currículos podem ser desenhados;

- Apesar de ambos os currículos serem do ETP, no novo currículo o conhecimento prático e profissional é mais enfatizado. O conhecimento teórico-abstracto, como a Matemática, é verbalizado (expressando-se, por exemplo, como "usar a matemática para resolver problemas quotidianos").

Portanto, para Zavale (2013b), os novos currículos do ETP são caracterizados pela inter ou transdisciplinaridade, verbalização, flexibilidade, practicalidade e profissionalização do conhecimento.

\section{Crítica social-realista ao currículo}

Zavale (2013a) tece críticas ao novo currículo do ETP, socorrendo-se no realismo social. Uma compreensão exaustiva dessas críticas exige uma apresentação dos fundamentos principais da teoria social-realista sobre o conhecimento e currículo.

\section{Da génese do debate curricular na sociologia da educação ao realismo social}

O realismo social emerge no contexto do debate existente no seio da SED sobre a natureza do currículo. Esse debate remonta às décadas de 1960 e 1970, quando a SED reivindicou legitimidade na análise do currículo, objecto ora considerado apanágio dos filósofos da educação. Os novos sociólogos da educação (NSE), como eram apelidados, entraram no debate curricular defendendo duas ideias (YOUNG, 1971). Por um lado, defendiam a relevância de a SED 
estudar os processos de transmissão do conhecimento por meio da escola, para além de apenas abordar a influência dos factores sociais como a estratificação social (BAUDELOT; ESTABLET, 1971) e a cultura (BOURDIEU; PASSERON, 1970) sobre a educação. Por outro lado, desafiavam a pretensa neutralidade do currículo, defendida pelos filósofos da educação (HIRST, 1969). Apoiando-se em bases teóricas eclécticas, como o marxismo, a teoria crítica, a sociologia weberiana, o interaccionismo simbólico, a fenomenologia social e o socioconstrutivismo, os NSE concebiam o currículo escolar não como entidade socialmente neutra, mas como construção social que reflecte relações de poder (YOUNG, 1971).

Três décadas passaram para que o socioconstrucvismo - a tese do currículo como construção social — fosse revisitado e resultasse em novas teorias. As críticas provieram de sociólogos e filósofos. Uns e outros acusavam o socioconstrutivismo de relativismo radical e igualitarismo epistemológico, isto é, de tentativa errónea de considerar como iguais todas as formas de conhecimento e todos os sujeitos cognoscentes (PRING, 1972; COOPER, 1980). Enquanto aceitavam parcialmente que o conhecimento podia ser produto da negociação social, os críticos argumentam que alguns aspectos do conhecimento têm bases epistemológicas objectivas. Essas críticas levaram os socioconstructivistas a reconsiderar suas teses, reconhecendo que o socioconstrutivismo tinha resultado em uma versão "pós-moderna do nihilismo nietzschiano", ao negar "qualquer possibilidade de progresso, verdade e conhecimento" (YOUNG; MULLER, 2007 , p. 181). Apesar desse reconhecimento, Young (2008, p. 7) rejeita, porém, a tese positivista de considerar o conhecimento como uma entidade neutra. Para ele (2008), as epistemologias relativista e positivista estão parcialmente erradas. A epistemologia relativista, ao considerar que todo o conhecimento é um constructo social, ignora a possibilidade de existência de propriedades epistemológicas que tornam algumas formas de conhecimento universalmente válidas ou, pelo menos, com validade para além dos contextos da sua produção. A epistemologia positivista, ao proclamar a neutralidade do conhecimento, ignora o facto de que todas as formas de conhecimento, incluindo a ciência, são produtos de acções humanas. Resultado disso é a "polarização entre a visão pós-moderna e positivista do conhecimento" (YOUNG, 2008, p. 25). O debate subjacente a essa polarização resultou numa teoria que procura ultrapassar tais clivagens: o realismo social (YOUNG, 2008; 2010; WHEELAHAN, 2010; MATON; MOORE, 2010).

\section{Realismo social}

O realismo social defende a possibilidade de convergência entre o socioconstrutivismo e o realismo a-social (YOUNG, 2008; WHEELAHAN, 2010; MATON; MOORE, 2010). Os social-realistas consideram, tal como 
os socioconstructivistas, que o conhecimento é social na sua origem e produção: o conhecimento é produzido num contexto de códigos e práticas colectivamente partilhadas pelos membros de comunidades específicas (YOUNG, 2008, p. 28-30). Mas o realismo social rejeita o argumento socioconstructivista de considerar a socialidade do conhecimento como conduzindo ao relativismo. Para o realismo social, a socialidade do conhecimento é a base para a sua objectividade. Conforme afirma Young (2010, p. 14), "é a base social do conhecimento que lhe confere objectividade e verdade, daí a mudança do socioconstrutivismo para o realismo social". O maior desafio do realismo social consiste em substituir a disjunção "ou/ou", implicada na polarização, para uma reformulada copulação "tanto/como" (MATON; MOORE, 2010, p. 2). $\mathrm{O}$ realismo social reconhece a objectividade do conhecimento, mas também a sua socialidade e falibilidade.

Assim, para os social-realistas, as formas de conhecimento não têm igual validade epistemológica. As propriedades do conhecimento teórico são diferentes das propriedades do conhecimento quotidiano. O conhecimento teórico é abstracto e conceptual; é produzido em contextos sociais específicos, mas seu poder explicativo transcende esses contextos e sua validade depende do acordo da comunidade científica. O conhecimento quotidiano é também produzido em contextos sociais específicos, mas seu poder explicativo restringe-se a esses contextos. Essas diferenças justificam diferenças de poder heurístico e legitimidade de aplicação. Os social-realistas consideram o conhecimento teórico mais poderoso do que o conhecimento quotidiano.

\section{A crítica social-realista ao currículo do ensino técnico-profissional}

Baseando-se nesses argumentos, Zavale (2013a; 2013b) defende que as características do novo currículo do ETP concorrem para a negligência do conhecimento teórico. $\mathrm{O}$ autor faz essa interpretação analisando o processo histórico das reformas educativas no Moçambique pós-colonial, nomeadamente a influência que as reformas sofreram do socialismo e do neoliberalismo. $\mathrm{O}$ autor baseia-se no socioconstrutivismo, no realismo associal e no realismo social. $\mathrm{O}$ autor argumenta que o socioconstrutivismo, com a sua tese do conhecimento e currículo como construçóes sociais veiculadoras de relaçôes de poder, foi o paradigma predominante nos períodos em que as ideologias socioeconómicas estavam em apogeu: socialismo (1975-1990) e neoliberalismo (de 2004 aos nossos dias); o realismo associal, com a sua tese da neutralidade do conhecimento, foi predominante no período de transição do socialismo para o neoliberalismo (1990-2004) - a transição tinha deixado um vazio ideológico (ZAVALE, 2013b, p. 632). Zavale interpreta os currículos dos períodos socialista e neoliberal como sendo ideológica e socialmente construídos: durante o socialismo, os currículos tendiam a ajustar-se 
à visão Marxista-Leninista do mundo; durante o neoliberalismo, os currículos procuram satisfazer o mercado. Tanto no socialismo como no neoliberalismo, as ideologias e forças sociais eram mais poderosas do que as disciplinas científicas. Mas durante o período transitório, os currículos escolares em Moçambique, incluindo o do ETP, tenderam a ser ideologicamente neutros e a basear-se sobretudo no conhecimento disciplinar.

Assim, Zavale tece críticas às reformas curriculares do Moçambique pós-colonial: as políticas curriculares foram inspiradas pelo que Maton (2013) apelidou de "knowledge blindness": ou os currículos eram baseados em forças sociocontextuais, sem base para a sua objectividade, ou eram baseados no ideal positivista da universalidade do conhecimento, sem referência a contextos sociais. Raramente as políticas curriculares procuraram conciliar a necessidade de satisfazer as demandas societais com a possibilidade de preservar os critérios de independência e objectividade do conhecimento. Assim, o novo currículo do ETP, com a sua tendência de negligenciar o conhecimento teórico, arrisca-se a prover os alunos de conhecimentos que servem os interesses (ideológicos) neoliberais, e não os interesses epistemológicos de desenvolvimento de conhecimento objectivo e independente. Essas críticas sugerem que as reformas curriculares deviam acompanhar as demandas societais, mas garantido a objectividade do conhecimento. São essas propriedades do conhecimento teórico que lhe conferem poder universal, cujo alcance transcende os contextos particulares da sua produção. Por isso, à semelhança de outros autores inspirados no realismo social (YOUNG, 2008; WHEELAHAN, 2009; 2010), Zavale (2013b, p. 633) faz um apelo: trazer o conhecimento teórico de volta ao currículo, porque é poderoso.

\section{Limites do realismo social}

As críticas social-realistas permitiram reconsiderar o lugar do conhecimento teórico no debate curricular. Contudo, segundo Shay (2012, p. 4-5), as mesmas resultaram numa teoria de diferenciação do conhecimento, e não de diferenciação curricular. $\mathrm{O}$ realismo social enfatizou as diferenças entre formas de conhecimento e não entre formas de currículos; considerou o conhecimento teórico como mais poderoso do que outras formas de conhecimento e, portanto, como devendo ser integrado em todos os currículos escolares. Todavia, o realismo social não permite saber o grau em que o conhecimento teórico é necessitado pelos diferentes currículos, para torná-los poderosos. Em outras palavras, o realismo social não providencia uma teoria que permita determinar a "quantidade" de conhecimento teórico ou outra forma de conhecimento necessária para as diferentes formas de currículos (ex. currículo disciplinar, profissional, vocacional). Para Shay (2012), o realismo social não fornece uma teoria que permita compreender os princípios determinantes do tipo de 
conhecimento seleccionado para os vários tipos de currículos. Shay (2012) propôs, então, esse modelo explicativo dos princípios de legitimação da diferenciação curricular.

\section{Teoria de diferenciação curricular de Shay}

A teoria de diferenciação curricular de Shay (2012) baseia-se na análise da reforma curricular no ensino superior sul-africano pós-Apartheid. Em 2004, o governo sul-africano criou a universidade compreensiva, fundindo os currículos profissionais e teóricos. Ao analisar dez cursos com currículo vocacional, profissional e geral, oferecidos pela universidade compreensiva, Shay concluiu que esses cursos tinham, em escalas diferentes, conhecimento prático e teórico. Shay formulou, então, uma teoria sobre os princípios orientadores do tipo de conhecimento seleccionado para integrar esses currículos, considerando a possibilidade de diferenças de bases de legitimação. A possibilidade de diferenças entre os currículos depende da diferença no processo de recontextualização e integração das diferentes formas de conhecimento nos diferentes tipos de currículos. Assim, enquanto o realismo social explica as diferenças entre formas de conhecimento, não consegue, todavia, explicar como essas formas são integradas nas diferentes práticas curriculares, com diferentes propósitos.

Conceptualmente, a teoria de Shay baseia-se nas teorias dos códigos pedagógicos e de estruturas de conhecimento de Bernstein, e na teoria dos códigos de legitimação (TCL) de Maton. De Bernstein, Shay retém a ideia de que as propriedades de conhecimento se alteram quando o conhecimento transita do lugar da produção para o lugar da sua recontextualização e transmissão. Assim, o conhecimento inserido no currículo (ex., o conhecimento do manual escolar de Física) encontra-se descontextualizado do seu contexto de produção (laboratório/departamento universitário de Física) e recontextualizado para objectivos pedagógicos (SHAY, 2012, p. 5). Da teoria de estruturas de conhecimento de Bernstein, Shay apropria-se da ideia da diferenciação entre o conhecimento vulgar e o teórico, e da descrição das estruturas do conhecimento nos lugares de produção. Para Bernstein (2000, p. 157-160), o conhecimento vulgar e o teórico diferem-se pela horizontalidade e verticalidade: o vulgar é contextualmente fundado e progride horizontalmente, por acumulação de novas linguagens; o teórico é descontextualizado e progride hierarquicamente por meio da integração do conhecimento prévio em proposiçóes mais gerais. A gramaticalidade constitui outro princípio bernsteniano diferenciador das estruturas de conhecimento das disciplinas académicas. Alguns campos de conhecimento, como a Economia, têm gramáticas fortes, isto é, possuem uma sintaxe conceptual explícita que permite fazer descriçōes empíricas precisas; outras formas de conhecimento, como a Antropologia, têm gramáticas fracas, por não possuirem essa 
sintaxe conceptual. Para Shay, a teoria de Bernstein permite tornar inteligíveis as estruturas de conhecimento nos lugares de produção. Ainda assim, Bernstein não consegue:

[d] escrever o que acontece quando o conhecimento é recontextualizado para objectivos curriculares. A progressão do conhecimento no lugar de produção é diferente da progressão no local da sua recontextualização e reprodução. Importa, por isso, alargar a teoria de Bernstein, para conceptualizar e analisar as relaçóes internas e externas do conhecimento recontextualizado (SHAY, 2012, p. 6).

Para ultrapassar esse problema, Shay recorre à TCL de Maton, particularmente à sua dimensão semântica. A semântica de Maton (2011) descreve a relação entre o significado contido nas proposiçóes de conhecimento e o contexto, bem como o grau de complexidade ou abstracção das proposiçóes de conhecimento. Maton baseia-se em dois conceitos: gravidade semântica (GS) e densidade semântica (DS). A GS refere-se ao grau em que o significado está relacionado ao contexto: as proposiçóes de conhecimento com forte GS encontram-se mais relacionadas ao contexto do que as com fraca GS; a DS refere-se ao grau de complexidade ou condensação do significado com os símbolos (termos, conceitos, frases etc.): quanto mais condensado for o significado com os símbolos, mais forte é a densidade semântica (MATON, 2011, apud SHAY, 2012, p. 6). A GS descreve as relaçóes externas do conhecimento; a DS, as relaçóes internas. A GS e a DS revelam o grau de (in)dependência das formas de conhecimento em relação ao contexto, bem como o quão essas formas se fundam em conceitos ou na experiência. No modelo de Shay, a combinação do grau da força da GS e DS resulta em quatro formas de conhecimento e, consequentemente, em quatro modelos curriculares (SHAY, 2012, p. 6-7).

Primeiro, formas de conhecimento com forte GS e DS são dependentes do contexto e possuem uma sintaxe conceptual muito complexa (ex. conhecimento profissional) - é o caso dos currículos do ETP: o currículo profissional, como o caso de Jornalismo na universidade compreensiva sul-africana, funda-se no conhecimento profissional. Nesse tipo de currículo, o conhecimento teórico é recontextualizado para ser útil ao contexto (SHAY, 2012, p. 13).

Segundo, formas de conhecimento com forte GS e fraca DS são dependentes do contexto, mas estão desprovidos de uma sintaxe conceptual densa (ex. conhecimento prático). O conhecimento prático resulta em currículos práticos, como o currículo de Reportagem Avançada na universidade compreensiva sul-africana. Os currículos práticos resultam da recontextualização do conhecimento prático em princípios orientadores de uma prática informada (SHAY, 2012, p. 11). 
Terceiro, formas de conhecimento com fraca GS e forte DS possuem uma sintaxe conceptual complexa, mas não se referem a nenhum contexto, constituindo-se em generalizações abstractas (ex. conhecimento teórico). Essas formas de conhecimento resultam em currículos teóricos, como o caso da Matemática no curso de Mecatrónica (SHAY, 2012, p. 12).

Quarto, formas de conhecimento com fracas GS e DS não dependem do contexto, nem possuem uma sintaxe conceptual (ex. conhecimento genérico). Essas formas de conhecimento, fracas em GS e DS, quando recontextualizadas nos currículos, traduzem-se em habilidades genéricas, como a capacidade crítica, a capacidade de trabalhar sob pressão, etc. As habilidades genéricas estão desprovidas de conceitos e não se referem a algum contexto específico.

Conforme mostra a Figura 1, Shay defende que o conhecimento integrado no currículo é diferente do conhecimento produzido nos lugares de produção. Nos lugares de produção, o conhecimento pode ser teórico (disciplinas científicas), prático (experiência prática) e profissional (experiência profissional). As possibilidades curriculares dependem do tipo de conhecimento predominantemente recontextualizado no currículo. O currículo teórico resulta da recontextualizaçâo do conhecimento teórico; o currículo profissional, da recontextualização do conhecimento teórico e do profissional; o currículo prático, da recontextualização da experiência prática; o currículo genérico, da recontextualização do conhecimento genérico (SHAY, 2012, p. 15).

\section{Figura 1}

Representação da teoria de diferenciação curricular de Shay (2012).

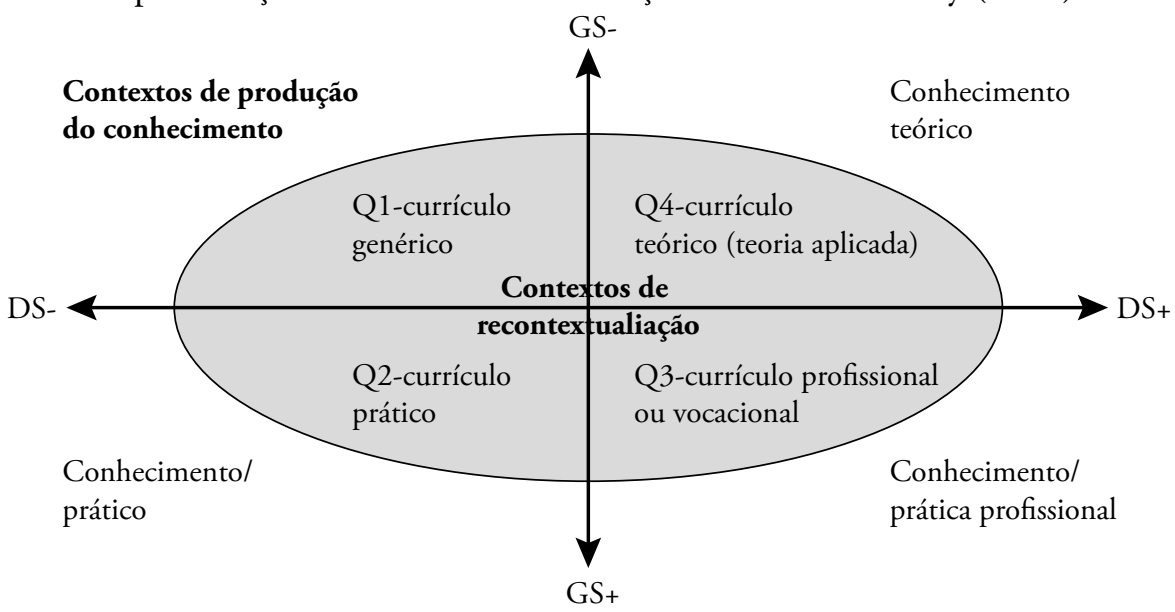

DS: densidade semântica; GS: gravidade semântica. 


\section{Relevância do modelo de Shay para análise da natureza do novo currículo de ensino técnico-profissional em Moçambique}

O modelo de Shay mostra que diferentes formas de conhecimento podem ser integradas no currículo, dependendo do tipo e do propósito do currículo. Se o propósito for a compreensão da realidade natural/social, o conhecimento teórico pode ser a forma de conhecimento mais apropriada para o currículo; mas, se o propósito for adquirir conhecimento útil à prática profissional, então os conhecimentos provenientes das disciplinas científicas e da prática profissional podem ser preferíveis. O modelo de Shay permite mostrar que, contrariamente às teses social-realistas, o conhecimento teórico não é requerido no mesmo grau pelos diferentes modelos curriculares. Isso pode significar que o conceito de conhecimento poderoso pode variar em funçáo do tipo de currículo. $\mathrm{O}$ modelo mostra, igualmente, que outras formas de conhecimento podem ser integradas no currículo, dependendo dos seus propósitos. Ademais, o modelo mostra que as formas de conhecimento, quando integradas no currículo, não mantêm intactas as propriedades adquiridas nos contextos da sua produção.

O presente artigo reinterpreta a reforma do currículo do ETP. Baseando-se no modelo de Shay (2012), o artigo problematiza as críticas social-realistas, descrevendo a natureza do "conhecimento poderoso" no currículo do ETP por meio da explicitação dos processos epistémicos e sociais condicionantes desse currículo. Com base em Shay, o artigo revisita a tendência social-realista de identificar a noçáo do conhecimento poderoso com conhecimento teórico. Pelo facto de, originalmente, o modelo limitar-se apenas a processos epistémicos (SHAY, 2012, p. 14-15), o artigo procura alargar o seu âmbito para incluir os processos sociais subjacentes ao currículo do ETP. Portanto, o modelo de Shay é usado para teorizar a especificidade do conhecimento poderoso num currículo de ETP.

\section{Princípios epistémicos e sociais do ensino técnico-profissional: reinterpretando o novo currículo do ensino técnico-profissional em Moçambique}

Baseando-se em exemplos de dois cursos, nomeadamente Electricidade Industrial e Gestão, as Tabelas 1 e 2 visualizam a natureza da recontextualização das competências genéricas e especificas no novo currículo. A Tabela 1 visualiza a recontextualizaçáo das competências genéricas e mostra os contextos e agentes de produção de conhecimento, que constituem a fonte das competências genéricas recontextualizadas no currículo. Conforme a tabela mostra, as competências genéricas integradas no novo currículo do ETP podem derivar de vários contextos e agentes de produçáo de conhecimento. Dependendo do tipo de competências 
genéricas, os contextos e agentes de produção de conhecimento podem ser específicos e não específicos. Por exemplo, as competências de relacionamento social, recontextualizadas no currículo, podem ser produzidas por agentes e contextos sociais não específicos; mas as competências em matemática e informática podem ser produzidas por contextos e agentes específicos, tais como a academia e os professores de informática e matemática. Algumas competências genéricas podem ser produzidas tanto por contextos e agentes específicos como não específicos: por exemplo, as competências de comunicação, recontextualizadas no currículo, podem ter como fonte contextos e agentes sociais não específicos, como também podem ter como fontes contextos e agentes sociais específicos, como a academia e os professores de linguas.

A Tabela 2, por seu turno, mostra a recontextualização das competências especificas no novo currículo do ETP. A tabela mostra os contextos e agentes de

\section{Tabela 1}

Contextos/agentes de produção do conhecimento recontextualizado em competências genéricas no novo currículo do ensino técnico-profissional dos cursos de Electricidade Industrial e Gestão.

\begin{tabular}{|c|c|c|c|c|}
\hline $\begin{array}{l}\text { Competências } \\
\text { genéricas }\end{array}$ & $\begin{array}{c}\text { Electricidade } \\
\text { Industrial }\end{array}$ & Gestáo & $\begin{array}{l}\text { Contexto de } \\
\text { produçáo do } \\
\text { conhecimento }\end{array}$ & $\begin{array}{l}\text { Agentes sociais } \\
\text { produtores de } \\
\text { conhecimento }\end{array}$ \\
\hline $\begin{array}{l}\text { Competências } \\
\text { comunicativas }\end{array}$ & $\begin{array}{c}\text { Comunicar em } \\
\text { inglês }\end{array}$ & $\begin{array}{l}\text { Usar o inglês } \\
\text { em situaçóes } \\
\text { profissionais, } \\
\text { sociais e pessoais }\end{array}$ & $\begin{array}{l}\text { Náo específico: } \\
\text { sociedade } \\
\text { mais ampla, } \\
\text { mercado laboral } \\
\text { e academia } \\
\text { (linguística e } \\
\text { ensino de inglês) }\end{array}$ & $\begin{array}{l}\text { Náo específicos: } \\
\text { agentes sociais } \\
\text { diversos, agentes do } \\
\text { mercado laboral, } \\
\text { académicos e } \\
\text { professores de inglês }\end{array}$ \\
\hline $\begin{array}{l}\text { Competências de } \\
\text { relacionamento } \\
\text { social }\end{array}$ & $\begin{array}{l}\text { Desenvolver } \\
\text { técnicas } \\
\text { individuais de } \\
\text { vida }\end{array}$ & $\begin{array}{l}\text { Manter relaçóes } \\
\text { sociais eficientes }\end{array}$ & $\begin{array}{c}\text { Náo específico: } \\
\text { sociedade mais } \\
\text { ampla }\end{array}$ & $\begin{array}{c}\text { Náo específicos: } \\
\text { agentes sociais } \\
\text { diversos }\end{array}$ \\
\hline $\begin{array}{l}\text { Competências } \\
\text { em matemática e } \\
\text { informática }\end{array}$ & $\begin{array}{l}\text { Introdução à } \\
\text { informática; } \\
\text { usar a } \\
\text { matemática } \\
\text { para resolver } \\
\text { problemas } \\
\text { quotidianos }\end{array}$ & $\begin{array}{c}\text { Resolver } \\
\text { problemas } \\
\text { e situaçōes } \\
\text { quotidianas } \\
\text { usando números } \\
\text { racionais }\end{array}$ & $\begin{array}{l}\text { Específico: } \\
\text { academia } \\
\text { (matemática e } \\
\text { informática) }\end{array}$ & $\begin{array}{l}\text { Específicos: } \\
\text { académicos e } \\
\text { professores de } \\
\text { matemática e } \\
\text { informática }\end{array}$ \\
\hline $\begin{array}{l}\text { Competências de } \\
\text { preparação ao } \\
\text { emprego }\end{array}$ & $\begin{array}{c}\text { Preparar-se } \\
\text { para o emprego }\end{array}$ & $\begin{array}{l}\text { Preparar-se para } \\
\text { o emprego }\end{array}$ & $\begin{array}{c}\text { Específico: } \\
\text { mercado laboral }\end{array}$ & $\begin{array}{c}\text { Específicos: } \\
\text { mercado laboral } \\
\text { (empregadores } \\
\text { operando em } \\
\text { sectores específicos } \\
\text { do mercado laboral) }\end{array}$ \\
\hline
\end{tabular}


produção de três formas de competências específicas recontextualizadas no currículo. As competências teórico-académicas, recontextualizadas no currículo, são produzidas por académicos ligados a disciplinas específicas. As competências profissionais são produzidas por profissionais experientes, associados a organizaçóes profissionais. As competências práticas são produzidas no local de trabalho, pelos indivíduos que efectivamente realizam o trabalho.

A Figura 2 sumariza os processos e agentes sociais e epistémicos envolvidos na produção do conhecimento recontextualizado no currículo do ETP, descritos nas Tabelas 1 e 2. Epistemologicamente, a Figura 2 mostra que quatro formas de conhecimento podem ser recontextualizadas para o currículo do ETP: genérico, prático, profissional e teórico. $\mathrm{O}$ conhecimento prático está presente no currículo do ETP por causa da sua forte GS, isto é, da sua forte capacidade de lidar com o contexto, com os problemas práticos enfrentados no local de trabalho. $\mathrm{O}$ conhecimento teórico encontra-se presente no currículo devido à sua forte DS ou verticalidade, isto é, à sua capacidade de conferir uma metalinguagem que permite orientar os graduados a lidar com problemas (des)conhecidos encontrados em contextos sociais mais amplos. Entre a verticalidade do conhecimento teórico e a contextualidade do conhecimento prático, o currículo recontextualiza também duas formas de conhecimento. Por um lado, o conhecimento genérico, fraco em DS e GS, encontra-se presente no currículo por ser capaz de dotar os graduados de

\section{Tabela 2}

Contextos/agentes de produção do conhecimento recontextualizado em competências específicas no novo currículo do ensino técnico-profissional dos cursos de Electricidade Industrial e Gestão.

\begin{tabular}{l|c|c|c|c}
\hline $\begin{array}{l}\text { Competências } \\
\text { específicas }\end{array}$ & $\begin{array}{c}\text { Electricidade } \\
\text { Industrial }\end{array}$ & Gestáo & $\begin{array}{c}\text { Contexto de } \\
\text { produçáo do } \\
\text { conhecimento }\end{array}$ & $\begin{array}{c}\text { Agentes sociais } \\
\text { produtores de } \\
\text { conhecimento }\end{array}$ \\
\hline $\begin{array}{l}\text { Conhecimento } \\
\text { teórico especifico }\end{array}$ & $\begin{array}{c}\text { Medir e calcular } \\
\text { variáveis } \\
\text { eléctricas }\end{array}$ & $\begin{array}{c}\text { Fazer cálculos e } \\
\text { tratamento de } \\
\text { dados estatísticos }\end{array}$ & $\begin{array}{c}\text { Específico: } \\
\text { disciplinas } \\
\text { académicas (Física } \\
\text { e Estatística) }\end{array}$ & $\begin{array}{c}\text { Específicos: } \\
\text { académicos } \\
\text { (físicos e } \\
\text { estaticistas) }\end{array}$ \\
\hline $\begin{array}{l}\text { Competências } \\
\text { profissionais }\end{array}$ & $\begin{array}{c}\text { Concepção e } \\
\text { instalaçáo de } \\
\text { circuitos de } \\
\text { comando em } \\
\text { edifícios }\end{array}$ & $\begin{array}{c}\text { Realizar tarefas } \\
\text { administrativas } \\
\text { e de assistência } \\
\text { à gestáo de } \\
\text { recursos } \\
\text { humanos }\end{array}$ & $\begin{array}{c}\text { Específico: } \\
\text { ordens } \\
\text { profissionais } \\
\text { (de engenheiros } \\
\text { eléctricos e } \\
\text { gestores) }\end{array}$ & $\begin{array}{c}\text { Específicos: } \\
\text { profissionais } \\
\text { experientes } \\
\text { (engenheiros } \\
\text { eléctricos e } \\
\text { gestores) }\end{array}$ \\
\hline $\begin{array}{l}\text { Competências } \\
\text { práticas especificas }\end{array}$ & $\begin{array}{c}\text { Aquisição de } \\
\text { competências } \\
\text { práticas sobre } \\
\text { o trabalho } \\
\text { em ambientes } \\
\text { industriais }\end{array}$ & $\begin{array}{c}\text { Realizar } \\
\text { tarefas ligadas } \\
\text { a obrigaçóes } \\
\text { fiscais, facturação } \\
\text { e gestão de } \\
\text { tesouro }\end{array}$ & $\begin{array}{c}\text { Específico: } \\
\text { local de trabalho } \\
\text { (organizaçóes } \\
\text { industriais e } \\
\text { comerciais) }\end{array}$ & $\begin{array}{c}\text { Específicos: } \\
\text { trabalhadores } \\
\text { de organizaçóes } \\
\text { industriais e } \\
\text { comerciais }\end{array}$ \\
\hline
\end{tabular}


competências para lidar com problemas enfrentados em situaçóes sociais diversas, cuja solução não demanda o domínio de uma metalinguagem específica. Por outro lado, o conhecimento profissional, forte em GS e DS, está presente por ser capaz de dotar os graduados de competências para lidar com os problemas estritamente profissionais, cuja soluçấo demanda o domínio da complexa metalinguagem profissional específica.

Além desses princípios epistémicos, a Figura 2 estende o modelo de Shay, esquematizando os agentes sociais condicionantes do currículo do ETP. Tal extensão fundamenta-se pelo facto de, originalmente, o modelo de Shay não incluir a dimensão social, não obstante a TCL de Maton $(2007 ; 2011)$, alicerce do pensamento de Shay, envolver essa dimensão. Com efeito, originalmente a teoria de Maton concebe os processos de legitimação de conhecimento como sendo orientados por dois princípios: legitimação social, em que o conhecimento é legitimado pelas relaçôes sociais entre conhecedores; e a legitimação epistémi$\mathrm{ca}$, em que o conhecimento é legitimado pela forma como este torna o mundo inteligível (MATON, 2007, p. 97). O modelo de Shay inclui apenas a dimensão epistémica da TCL.

\section{Figura 2}

Representação dos processos epistémicos e sociais envolvidos na recontextualização curricular do ensino técnico-profissional (adaptado de SHAY, 2012). Sociedade mais ampla: diversos

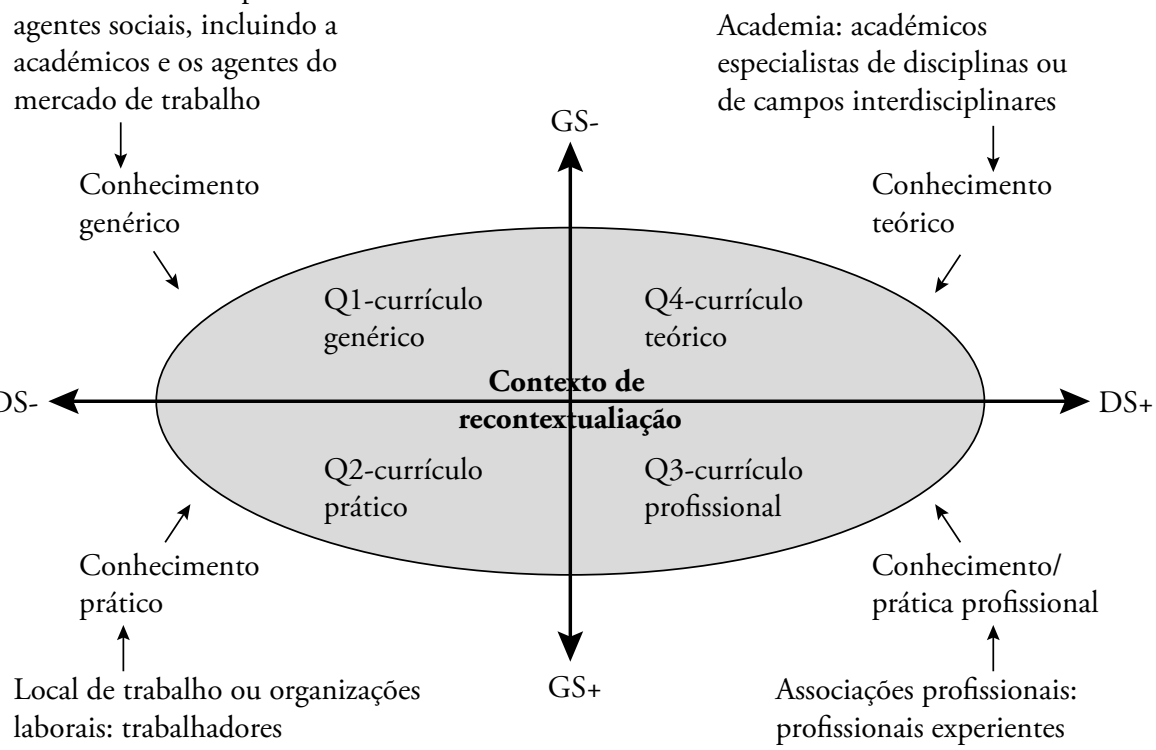

DS: densidade semântica; GS: gravidade semântica 
A Figura 2 mostra que quatro contextos podem ser responsáveis pela produção do conhecimento integrado no currículo: sociedade no geral, mercado de trabalho, academia e organizaçóes profissionais. No seio desses contextos, os seguintes agentes podem produzir conhecimento a recontextualizar no currículo: agentes sociais diversos, agentes do mercado, académicos, profissionais experientes e trabalhadores com experiência prática. Os agentes sociais diversos e os agentes do mercado produzem conhecimento genérico, recontextualizável em competências genéricas; os académicos produzem conhecimento teórico, recontextualizável em teorias aplicadas; os profissionais experientes produzem conhecimento profissional, recontextualizável em competências profissionais; os trabalhadores com experiência prática produzem conhecimento prático, recontextualizável numa prática informada. A estrutura do currículo do ETP é condicionada pela distribuição do poder e influência entre esses contextos e agentes. Em sociedades onde os académicos sáo mais poderosos, o currículo tenderá a recontextualizar o conhecimento teórico-disciplinar; em sociedades onde as ordens profissionais e os trabalhadores são mais poderosos, a predominância tenderá a recair sobre o conhecimento prático e profissional. $\mathrm{O}$ caso Moçambicano mostra que várias formas de conhecimento podem ser recontextualizadas no ETP, sendo que a predominância de umas sobre as outras dependerá de processos de regulação social.

Assim, conforme esquematiza a Figura 3, a natureza do conhecimento poderoso no ETP não se funda em torno do conhecimento teórico, mas em torno da combinação, nem sempre equilibrada, de quatro formas de conhecimento. No núcleo dessa combinação, encontra-se o conhecimento profissional, que é simultaneamente forte em DS e GS, isto é, que é vertical - tem uma metalinguagem especializada - e contextual — refere-se a um contexto concreto, o contexto de trabalho/tarefas profissionais. $\mathrm{Na}$ periferia desse núcleo, três formas de conhecimento orbitam: primeiro, o conhecimento prático, forte em GS ou contextualidade — por ser adquirido por meio da experiência prática no contexto ou local de trabalho — e fraco em DS ou verticalidade — por ser desprovido de um sistema conceptual capaz de ordenar as experiências práticas; segundo, o conhecimento genérico, fraco em DS e GS, mas relevante para as chamadas competências transversais, necessárias para lidar com os contextos profissionais e não profissionais mais amplos; terceiro, o conhecimento teórico, forte em DS e fraco em GS, reforça a metalinguagem presente no conhecimento profissional, sobretudo por meio da adequação dessa metalinguagem ao contexto específico do trabalho profissional.

Aliás, baseando-nos em teóricos da formação/exercício profissional, que caracterizam o conhecimento e a prática profissionais como consistindo na confluência de diferentes formas de conhecimento, podemos sustentar a tese de que o poder do currículo do ETP reside, sobretudo, na possibilidade de recontextualização desses conhecimentos: conhecimento proposicional ou 
codificado, conhecimento tácito, conhecimento pessoal, conhecimento profissional, conhecimento prático, conhecimento cultural, "craft knowledge" e conhecimento reflexivo (ver SCHÖN, 1983; DREYFUS; DREYFUS, 1986; ERAUT, 1994).

\section{Considerações finais}

Tendo como base a teoria de diferenciação curricular de Shay, e o novo currículo do ETP de Moçambique, o presente artigo procurou descrever a natureza do "conhecimento poderoso" no currículo do ETP, assim como os processos epistémicos e sociais que o condicionam. O argumento central do artigo é de que o conceito de conhecimento poderoso, enraizado no realismo social, pode variar em função da natureza do currículo. No ETP, esse conceito pode resultar da combinação de várias formas de conhecimento (genérico, prático, profissional e teórico) que, agregadas e recontextualizadas no currículo, permitiriam fazer face ao duplo problema do ETP: a contextualidade e a verticalidade (BARNETT,

\section{Figura 3}

Natureza do conhecimento poderoso no currículo do ensino técnico-profissional.

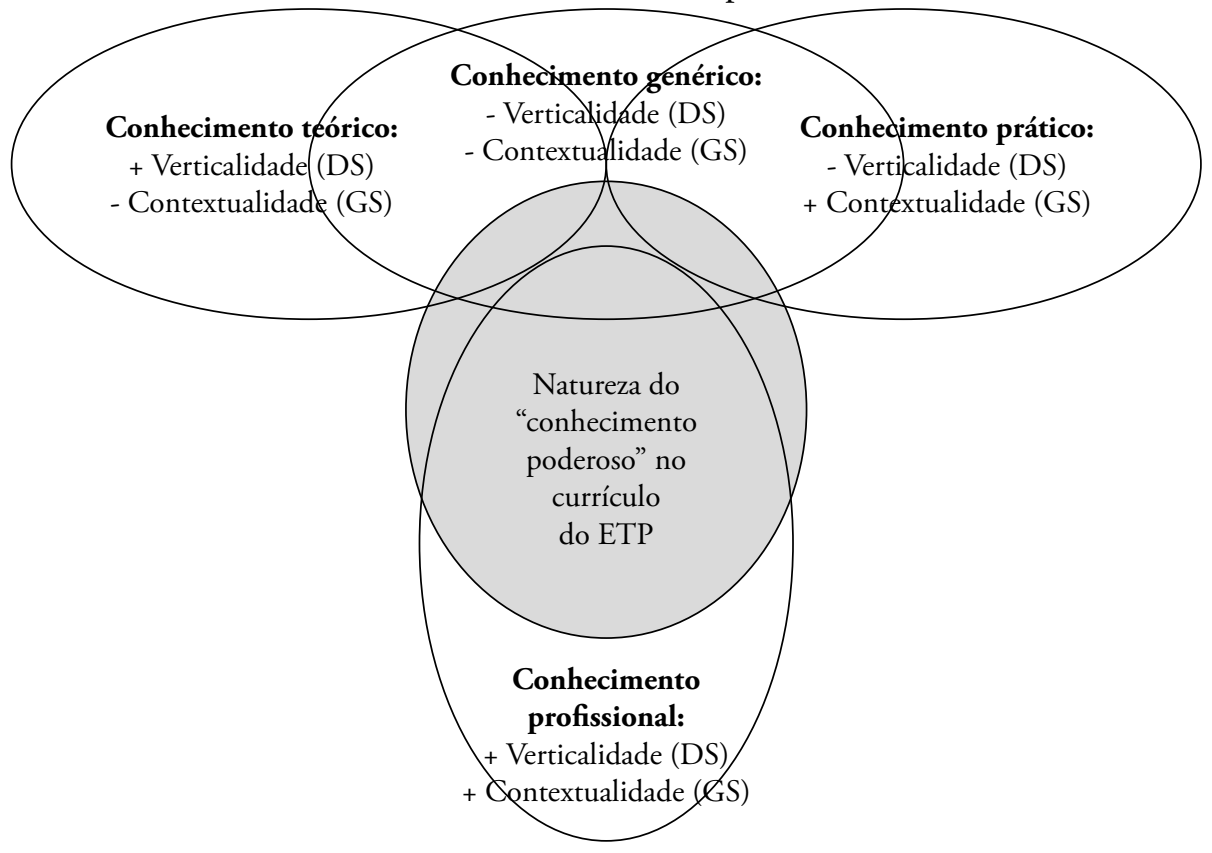

DS: densidade semântica; GS: gravidade semântica; ETP: ensino técnico-profissional. 
2006). O conhecimento teórico ajuda a verticalizar o currículo do ETP, conferindo-lhe um modelo conceptual com validade e objectividade universal; o conhecimento genérico ajuda o ETP a lidar com os problemas encontrados em contextos sociais mais amplos, cuja solução pode não requerer conhecimento vertical; o conhecimento profissional e o prático ajudam a "contextualizar" o ETP, por meio do uso ou não da metalinguagem conceptual. Por fim, se todas essas formas de conhecimento são recontextualizáveis para o currículo do ETP, o seu formato final dependerá de processos de regulação social entre diferentes produtores de conhecimento: Estado, empregadores, académicos, associaçôes profissionais e trabalhadores.

\section{Referências}

ABRAHAMSON, H.; NILSON, A. Mozambique: the troubled transition - from socialist construction to free market capitalism. London: Zed Books, 1995.

ATCHOARENA, D.; DELLUC, A. Revisiting technical and vocational education in Sub-Saharan Africa: an update on trends, innovations and challenges. Paris: IIEP/ Unesco, 2002.

BARNETT, M. Vocational knowledge and vocational pedagogy. In: YOUNG, M.; GAMBLE, J. (Orgs.). Knowledge curriculum and qualifications for South African further education. Pretoria: Human Resources Research Council Press, 2006. p. 143-157.

BAUDELOT, C.; ESTABLET, R. L’école capitaliste en France. Paris: Maspero, 1971.

BERNSTEIN, B. Pedagogy, symbolic control and identity: theory, research, critique. Lanham, MD: Rowman \& Littlefield Publishers, 2000.

BOND, P. Neo-liberalism in Subsaharan Africa: from Structural Adjustment to NEPAD. In: SAAD, J.; JOHNSON, D. (Orgs.). Neo-liberalism: a critical reader. London: Pluto Press, 2005.

BOURDIEU, P.; PASSERON, J.-C. La Réproduction: élements pour une théorie du système d'enseignement. Paris: Minuit, 1970.

COOPER, D. Illusions of Equality. London: Routledge and Kegan Paul, 1980.

DREYFUS, H.L.; DREYFUS, S.E. Mind over Machine: The Power of Human Intuition and Expertise in the Era of the Computer. Oxford: Basil Blackwell, 1986.

ERAUT, M. Developing Professional Knowledge and Competence. London: Falmer, 1994.

HIRST, P. The logic of the curriculum. Journal of Curriculum Studies, v. 1, n. 2, p. $142-158,1969$.

LANGA, P.V. A mercantilização do ensino superior e a relação com o saber: a qualidade em questão. Revista Cientifica da UEM: Série Ciências da Educação. v. 1, n.1. p. 21-41, 2012. 
LANGA, P.V.; ZAVALE, N.C. Private higher education in Mozambique: an overview of a growing subsystem. Working Papers in Higher Education Studies, v. 1, n. 2, p. 88-109, 2015.

MATON, K. Knowledge and knowers: towards realist sociology of education. London: Routledge, 2013.

- Knowledge-knower structures in intellectual and educational fields. In: CHRISTIE, F.; MARTIN, J. (Orgs.). Language, Knowledge and Pedagogy: Functional Linguistic and Sociological. London: Continuum, 2007. p. 87-108.

Theories and things: the semantics of disciplinarity. In: CHRISTIE, F.; MATON, K. (Orgs.). Disciplinarity: systemic functional and sociological perspectives. London: Continuum, 2011. p. 62-84.

MATON, K.; MOORE, R. (Orgs.). Social Realism, Knowledge and the Sociology of Education: Coalitions of the Mind. London: Continuum, 2010.

MOORE, R. Social realism and the problem of knowledge in the sociology of education. British Journal of Sociology of Education, v. 34, n. 3, p. 333-353, 2013. [cited 2013 Feb 20]. Available from: http://www.tandfonline.com/doi/abs/10.1080/01425692.2012.714251. Acessed from:

PRING, R. Knowledge Out of Control. Education for Teaching, v. 89, automne, p. 19-28, 1972. [cited 2013 Dec 15]. Available from: https://eric.ed.gov/?id=EJ077107.

REPÚBLICA DE MOÇAMBIQUE. Estratégia do Ensino Técnico-Profissional em Moçambique 2002-2011: mais técnicos, mais profissóes, melhor qualidade. Maputo: Conselho de Ministros, 2001.

SCHÖN, D. The Reflective Practitioner: How Professionals Think in Action. New York: Basic Books, 1983.

SHAY, S. Conceptualising curriculum differentiation in higher education. British Journal of Sociology of Education, p. 1-20, 2012. [cited 2013 Jan 20]. Available from: http://www. legitimationcodetheory.com/pdf/2013Shay.pdf.

WHEELAHAN, L. The problem with CBT (and why constructivism makes things worse). Journal of Education and Work, v. 22, n. 3, p. 227-242, 2009.

Why knowledge matters in curriculum: a social realist argument. London: Routledge, 2010.

YOUNG, M. Bringing knowledge back in: from social constructivism to social realism in the sociology of education. London: Routledge, 2008. . Knowledge and Control. London: Collier-Macmillan, 1971.

. Why educators must differentiate knowledge from experience. The Journal of the Pacific Circle Consortium for Education, v. 22, n. 1, p. 9-20, 2010.

YOUNG, M.; MULLER, J. Truth and Truthfulness in the sociology of educational knowledge. Theory and Research in Education, v. 5, n. 2, p. 174-201, 2007. 
ZAVALE, N. Diagnóstico das necessidades de formação dos professores em exercício nos institutos médios agrários de Moçambique. Revista Cientifica da UEM, no prelo.

. Le néolibéralisme et l'éducation: vers l'émergence de l'approche par compétence sur les curricula scolaires. Saarbrücken: Presses Académiques Francophones, 2013a.

Using Michael Young's analysis to examine the effects of Neo-liberalism on curricula in Mozambique. Policy Futures in Education, v. 11, n. 5, p. 621-636, 2013 b.

Recebido em 07 de agosto de 2015.

Aprovado em 22 de março de 2017. 